\title{
Основные направления перцептивно-логической эволюции лексики русского языка
}

\author{
СЕРГЕЙ ПОПОВ \\ Кафедра русского языка Харьковского национального университета имени В. Н. Каразина, \\ площадь Свободы, 4, UA-61022 Харьков \\ E-mail: s.leon.popov@gmail.com
}

(Received: 15 March 2017; accepted: 12 June 2017)

\begin{abstract}
The purpose of this paper is to analyze the manifestations of the influence of perceptual-logical components of thinking on the evolutionary processes in the Russian lexis. The study is in line with a cognitive and evolutionary approach. Based on the information of anthroponymic sciences about degrees of perception and the quality of logics, this approach allows to take a deeper view on the main reasons of the phenomena. The review of historical transformations of the Russian lexis in terms of its perceptual-logical evolution suggests that native speakers of Russian tend to optimize the lexical system of Russian in a logical way: 1) by generalizing the lexical meanings; 2 ) by creating abstract vocabulary; 3 ) by word formation with the help of a variety of derivational means, including borrowings; 4) by overcoming mnemonic shortage using two available, metaphorical and metonymic, opportunities to create new lexical meanings; 5) by getting rid of the logical inconsistency of polynomials; 6) by distinguishing words derived from Church Slavonic and their native Russian equivalents; 7) by getting rid of the vernacular, not required for communication by the overwhelming majority of native speakers; 8 ) by logically returning obsolete nominations for communication needs; 9) by continuing the development of polysemy at the present time.
\end{abstract}

Keywords: lexicology, Russian, lexis, perception, logic, evolution

0. Хорошо известно, что естественные языки с течением времени изменяются на всех своих ярусах. Это убедительно доказано трудами представителей сравнительно-исторического языкознания. Для большинства лингвистов языковые изменения являются абсолютным синонимом проявлений аксиоматически прогрессивного развития языка. Однако встречается также различение прогрессивного и непрогрессивного языкового развития. Вследствие такого различения по-разному трактуется и понятие языковой эволюции. Например, Б. А. Серебренников отождествляет эволюцию с прогрессом и различает относительный и абсолютный языковые прогрессы (СЕРЕБРЕНников 1970), а Н. В. Юдина различает в языке «просто изменения», которые называет эволюцией, и «изменения прогрессивные» (ЮдинА 2010: 264-265).

Когнитивно-эволюционный подход, предложенный эволюционной эпистемологией к изучению закономерностей познания явлений действительности и примененный к изучению механизма стихийной и сознательной дифференциации русских грамматических вариантов (Попов 2015), позволил осознать правоту Б. А. Серебренникова и других лингвистов, склонных считать 
языковые изменения прогрессивными, и признать эволюцию языка потенциально позитивной, характеризующейся высокой степенью позитивной реализации. Основой для такого признания стала фиксация когнитивно-эволюционного алгоритма «восприятие $\rightarrow$ логичность мышления $\rightarrow$ логичность грамматики». Восприятие может быть: 1) синкретичным, то есть целостным, не позволяющим дифференцировать признаки и, следовательно, категоризировать познаваемое; 2) поверхностным, то есть ориентированным на ближайшие, наиболее заметные, «лежащие на поверхности» признаки, по которым и происходит категоризация, часто ошибочная; 3) альтернативным, то есть ориентированным на все имеющиеся в наличии признаки, благодаря чему может быть выбран признак, категоризация по которому корректна. Каждая из этих степеней восприятия обеспечивает соответствующее качество логичности мышления и, как следствие, логичности тесно связанной с мышлением грамматики (подробнее об этом см. Попов 2015: 64-142). Однако очевидно, что перцептивно обусловленное качество логичности мышления влияет не только на грамматический строй - в той или иной степени оно влияет на язык в целом, то есть на все его уровни, обусловливая соответствующее качество их логичности.

Цель настоящей статьи - рассмотреть проявления влияния перцептивнологической составляющей мышления на эволюционные процессы в лексическом строе русского языка.

1. Начнем с бесспорного положения, что от лексического разнообразия языка зависит его смыслоразличительная способность (условимся считать смыслоразличение общим понятием, включающим и семантические, и стилистические различия): чем больше слов, тем качественнее такая способность. Известно, что языки первобытных народов, равно как и начинающих говорить детей (изоморфизм филогенеза и онтогенеза, гипотетически отмеченный в свое время Л. С. Выготским, в настоящее время несомненен - см. БАрулин 2008: 52), имеют относительно мало слов, поскольку в познанной ими действительности нет такого количества объектов, для обозначения и различения которых понадобилось бы большое количество номинаций. По мере расширения сферы познания увеличивается потребность в смыслоразличении. Когда носители языка подсознательно воспринимают эту потребность, они так же подсознательно осуществляют деятельность, компенсирующую недостаток количества номинаций, а именно создают или, что проще, заимствуют новые слова. Создание слов во всех языках разнится: носители разных языков создают слова по совершенно разным внутренним формам, - что, с точки зрения эволюционной эпистемологии, неудивительно: присущая человечеству и трудно преодолеваемая поверхностность восприятия обусловливает случайность выбора признака, который кладется в основу номинации. Еще И. С. Рижский по этому поводу замечал: «Представим себе, что несколько человек смотрят в одно время на один огромный предмет. Поелику никто из них не в состоянии объять его всем своим взором, то один видит только одну, другой другую, и так далее, притом иной самую важную, иной, напротив, 
малозначащую его часть. Подобно сему первоначально действует на умы разных народов всякий предмет» (Рижский 1973: 37). Неудивительно, что «блуждание взора», неспособность зафиксировать существенные признаки предметов наблюдается и у младших дошкольников (Эльконин 2005: 205). Случайность выбора признака номинации коррелирует со случайным выбором того или иного пути эволюции человечества. Как убедительно констатирует Л. Б. Вишняцкий, «наша состоявшаяся эволюционная история - это только один из многих потенциально существовавших ее сценариев, который, в отличие от других, не остался запасным лишь в силу во многом случайного стечения мало связанных между собой обстоятельств» (Вишняцкий 2004: 7).

2. Рассмотрим проявления влияния перцептивно-логической составляющей мышления на эволюцию лексического состава русского языка.

2.1. Прежде всего обращает на себя внимание способность носителей языка обобщать в одной номинации целый класс сходных предметов, то есть формировать понятие, лежащее в основе лексического значения. Такая способность развилась у человека по исключительно биологической причине: объем человеческой памяти не позволяет создавать и запоминать большое количество разных номинаций, особенно для сходных явлений. Об этом писал еще И. М. Сеченов: «Если бы человек запоминал каждое из впечатлений в отдельности, то от предметов наиболее обыденных, каковы, например, человеческие лица, стулья, деревья, дома и пр., составляющих повседневную обстановку нашей жизни, в голове его оставалось бы такое громадное количество следов, что мышление ими, по крайней мере в словесной форме, стало бы невозможным, потому что где же найти десятки или сотни тысяч разных имен для суммы всех виденных берез, человеческих лиц, стульев и как совладать мысли с таким громадным материалом?» (Сеченов 1952: 317). Но сейчас для нас важно другое: обобщение явлений по интегральным признакам возможно только при одновременном восприятии этих явлений, то есть при альтернативном их восприятии, которое в онтогенезе и филогенезе проявляется как результат перцептивно-логической эволюции от синкретичного восприятия через восприятие поверхностное. Именно поэтому для взрослого в значении слова шкаф обобщены все разновидности шкафов, в то время как для ребенка, еще не покидавшего пределы детской, находящийся в ней шкаф - единственный в мире, как единственной в мире является гора для живущих около нее и не видящих других гор первобытных людей.

2.2. Поскольку одним из признаков литературного языка является «приспособленность не только для обозначения всей суммы знаний, накопленных человечеством, но и для осуществления отвлеченного, логического мышления» (ГорБАЧЕВич 1989: 7), лексика языка должна располагать соответствующими абстрактными словами. Неудивительно, что в истории лексического состава русского языка, как во многом и в речи ребенка, наблюдается постепенное количественное увеличение как слов вообще, демонстрирующее количественный рост формируемых в процессе познания понятий, так и слов отвлеченных, или абстрактных, свидетельствующее о логическом развитии 
(взрослении по детскому типу) мышления носителей языка. Так, Ф. И. Буслаев обращает внимание на абстрагирование -де, происшедшего от дееши и ставшего односложным обобщенным показателем чужой речи (OH-де там был), а также застывшей и десемантизированной формы повелительного наклонения гляди (Того и гляди, пойдет дождь) (БуслАЕВ 1959: 266).

Подавляющее большинство слов исконно русских: индоевропейских, общеславянских, восточнославянских и собственно русских, - а также определенная часть слов заимствованных представляют собой термины родства, названия животных, растений, продуктов питания, простых действий и качеств, то есть конкретную лексику. C XIV века начинают постепенно появляться слова абстрактные: ум, истина, добро, мысль, итог, осторожность, обман и другие (Филин 2006: 516-624, ТруБАЧЕВ 1991: 155-208, ШАНСКИй 1972: 70-86, ЧЕРных 1962: 338-353, 357-365, ШМЕЛЕВ 1977: 234-243, ФОМИНА 1990: 162-176). В памятниках Московской Руси значительно расширяются ассортимент русских слов и жанровое разнообразие их употребления (БулАховский 1958: 21-31). Лексическое взросление языка, аналогичное пополнению лексического запаса у подрастающего ребенка, происходит по принципу «от конкретного к абстрактному». Не возникает сомнений в том, что различение конкретного и абстрактного возможно только при альтернативности восприятия.

Однако нельзя не заметить, что по логичной частотности применения абстрактной лексики русский язык нередко уступает германским и романским языкам. Например, Ребенок подползал к краю обрыва переводится на французский язык системно: как L'enfant rampait jusqu'au bord de la pic. Но Змея подползла $к$ своей норе переводится на французский как Le serpent s'est approché de son trou (французский глагол является прямым эквивалентом русского приблизилась); Он пишет стихи переводится на французский как Il fait des vers (французский глагол является прямым эквивалентом русского делает). С французской точки зрения, информация о том, что ребенок подползал, выглядит коммуникативно востребованной, поскольку является уточняющей, ведь ребенок к краю обрыва мог подходить или подбегать. Но информация о том, что змея к норе подползает, а стихи пишутся, для франкофона избыточна (логически противоречива), поскольку и без уточнения понятно, что змея только ползает, а не, скажем, бегает или ходит, а стихи обычно пишутся, а не, к примеру, рисуются или выцарапываются на стене острым предметом. В таких не требующих уточнения случаях носители французского языка, в отличие от носителей русского языка, могут обходиться абстрактной лексикой.

2.3. Убедительным доказательством достижения носителями русского языка уровня перцептивной альтернативности является стихийно-активное использование стихийно созданных ими же весьма разнообразных (альтернативных) деривационных возможностей русского языка для создания новых слов от различных частей речи, например, от существительного земля в разных его значениях образованы земляной, землистыли, земной, земельнылй, на- 
земный, земляк, землекоп, землемер, землевладелеи, заземлить, заземление и другие. Показательно, что этот процесс охватил и заимствования. Так, оказавшуюся в русском языке иноязычную номинацию его носители без какихлибо затруднений не только подвергают русской фонетико-грамматической аккомодации, но и с помощью аффиксов образуют другую часть речи с новым лексическим значением, например, итальянское существительное concerto преобразуют в русское существительное концерт, а от него с помощью суффикса (звуковой и морфологический аспекты намеренно оставляем в стороне как лишь сопутствующие появлению нового лексического значения) создают прилагательное конщертный; английское существительное interview аккомодируют в русское существительное интервью, от которого с помощью суффикса образуют глагол интервьюировать, а от него так же суффиксально образуют процессуальное существительное интервьюирование; заимствованное английское существительное upgrade «компьютерщики» некоторое время используют как просто аккомодированное существительное (сделать апгрейd), но очень скоро с помощью суффикса создают (пока профессионально-жаргонный) глагол апгрейдить. Такая обусловленная альтернативностью восприятия свобода деривации носителям индоевропейских языков кажется делом обыденно-привычным. Однако осознать его прогрессивную значимость несложно в сравнении с языками, в которых такая свобода деривационных действий невозможна, например, в сравнении с языками изолирующими.

2.4. Особым, не простым в плане истории его становления видом перцептивно-логической эволюции лексического состава языка является развитие у имеющихся слов переносных значений.

2.4.1. Общеизвестно, что в русском языке, как и во всех остальных языках, наблюдается асимметрия: «отступление от упорядоченности, регулярности, единообразия в строении и функционировании языковых единиц, отражающее одну из основных особенностей строения и функционирования естественного языка» (ГАК 1990: 47). В свое время С. Карцевский так объяснил природу упомянутой асимметричности: «Всякий знак является потенциальным „омонимом“ и „синонимом“ одновременно, т. е. он образуется скрещением этих двух рядов мыслительных явлений... Если бы знаки были неподвижны и каждый из них выполнял только одну функцию, язык стал бы простым собранием этикеток» (КАРцЕВский 1965: 85). «Обозначающее (звучание) и обозначаемое (функция) постоянно скользят по „наклонной плоскости реальности“. Каждое „выходит“ из рамок, назначенных для него партнером: обозначающее стремится обладать иными функциями, нежели его собственная, обозначаемое стремится к тому, чтобы выразить себя иными средствами, нежели его собственный знак» (КАРцЕВский 1965: 90). Как видим, объяснение С. Карцевского, концентрирующее внимание на омонимичности и синонимичности лингвистических знаков, позволяет объяснить и причины появления переносных значений: потребностью языка в динамике существования. Однако, вероятнее всего, причина переносности состоит не 
столько в динамической потребности, сколько в упомянутой выше ограниченности объема человеческой памяти. Этому тезису есть достаточно убедительное доказательство от противного. К примеру, Б. Л. Уорф следующим образом сравнивает и комментирует метафоричность английского (заключая метафоры в кавычки) и аметафоричность индейского языка хопи: «Я „схватываю“ „нить“ рассуждений моего собеседника, но если их ,уровень“ слишком „высок“, мое внимание может ,рассеяться“ и ,потерять связь“ с их ,течением“, так что, когда он „подходит“ к конечному „пункту“, мы расходимся уже „широко“ и наши „взгляды“ так „отстоят“ друг от друга, что „вещи“, о которых он говорит, „представляются“ очень условными или даже „нагромождением“ чепухи. Поражает полное отсутствие такого рода метафор в хопи» (УоРф 1960: 151). То, что поражает Б. Л. Уорфа, вполне объяснимо: в языке хопи, отражающем скромные результаты познания действительности его носителями, еще не развилась метафоричность лексики, поскольку в этом развитии не было потребности: существующих на тот момент номинаций для коммуникации было достаточно. Это, как известно, особенность всех первобытных языков и - на ранней стадии развития - языков цивилизованных: отсутствие переносных значений и абстрактных существительных. Ребенок, постепенно познающий слова родного языка, вначале демонстрирует полное соответствие пути такого познания законам логики: исходит из принципа контраста, то есть полагает, что каждому новому понятию должно соответствовать новое слово (см. CLARK 1993) (этим принципом руководствуются, как выяснилось, даже собаки - Bцоом 2004). Лишь затем растущийпознающий человек воспринимает возможность нескольких смыслов для одной формы (делать многозначным один и тот же сигнал - по причине ограниченности ассортимента таких сигналов при насущной потребности выразить больше важной для выживания информации - вынуждены и животные; см. БурЛАК 2011: 244-245).

2.4.2. Поскольку причина переносности лексических значений ясна, важно понять, насколько когнитивно-эволюционными по своей природе являются виды такой переносности - метафора и метонимия. Психологические сведения (см. об этом Попов 2015: 119-136) позволяют понять, что при любом переносе значения как удовлетворении потребности создать новое значение воспринимаются лишь те признаки (семы), которые в первую очередь замечаются как похожие (метафора) или в первую очередь обращают на себя внимание как понятийно соседние, смежные (метонимия). То есть при переносе значений, как и при познании мира ребенком, воспринимается только то, что наиболее заметно благодаря сходству по какому-то признаку (при метафоре) или благодаря тому, что находится в непосредственной близости (при метонимии). Это проявления поверхностного восприятия.

Показательно в таком перцептивном плане и то, что из двух фиксируемых сегодня видов переносных значений метафора попала в поле зрения лингвистов в первую очередь. Еще И. М. Сеченов считал очень важной для процесса познания регистрацию впечатлений не только по сходству, но и по 
смежности: «всякое впечатление воспроизводится в тех же самых главных направлениях, в которых по сходству и смежности оно зарегистровывается в памяти, по сходству и смежности в пространстве и времени» (СЕченов 1952: $330)$, - но по понятной, научно мировоззренческой, причине - концентрации на самом языке с подчеркнутым безразличием к достижениям других наукструктуралисты Сеченова не читали.

В существующих советских и постсоветских толковых словарях переносный синонимически толкуется через иносказательный, метафорический, то есть лексическая метонимия в них не учитывается. В широко известном в русистике «Словаре лингвистических терминов» О. С. Ахмановой переносный толкуется как абсолютный синоним метафорический (АхмАновА 1969: 319), и не более того. Только в «Словаре-справочнике лингвистических терминов» Д. Э. Розенталя и М. А. Теленковой переносное значение рассматривается в более широком аспекте: «Перенос значения происходит на основе сходства предметов по форме, по цвету, по характеру движения, на основе выполняемой предметом функции, на основе ассоциации по смежности (пространственной, временной и т. д.)» (РозЕнтАЛь-ТЕЛЕнковА 1985: 201). Продемонстрированное выше обращение внимания прежде всего на метафору понятно: основанная на механизме сравнения, она гораздо заметнее метонимии (поверхностность восприятия).

2.4.3. Важным для понимания когнитивных корреляций метафоры и метонимии оказалось открытие, сделанное Р. Я. Якобсоном. Исследуя афазию с языковедческих позиций, ученый пришел к выводу о существовании двух лингвистических типов афазии: блокировки восприятия подобия (сенсорная афазия) и блокировки восприятия смежности (эфферентная афазия) (ЯкоБсон 1985). Автор проницательно связал эти виды афатической блокировки с метафорой, для которой центральным является понятие подобия (сходства), и метонимии, для которой центральным является понятие смежности: «Метафора не свойственна расстройствам подобия, а метонимия - расстройствам смежности» (Якоьсон 1990: 126). Однако сделанные Р. Я. Якобсоном выводы свидетельствуют о большем. Ученый в других терминах говорит о парадигматических (оппозиции) и синтагматических (позиции) отношениях в языке в целом, которые таким образом еще раз обнаруживают свою фундаментальную значимость для связи языка со строем мышления - логикой, распределяющим познаваемое по парадигмам и фиксирующим синтагматику элементов таких парадигм. Несомненной является корреляция метафоры с понятиями парадигматики, языка и - в философском аспекте - с понятиями абстрактности и теории, а метонимии - с понятиями синтагматики, речи и - в философском аспекте - с понятиями конкретности и практики (см. КуБРяковА 1990а, КуБРяковА 1990b). Из этого следует, что корреляция метафоры и метонимии с вынужденной, обусловленной небезразмерностью памяти поверхностностью восприятия - фундаментальное свойство человеческой когниции, эволюционирующей от синкретизма - через промежуточное звено поверхностности - к альтернативности. 
2.4.4. В целом можно говорить о том, что носители русского языка, стихийно отреагировав на присущий им биологический недостаток - ограниченность объема памяти, альтернативно восприняли две доступные им, значимые для человеческого мышления возможности создавать новые лексические значения - путем метафорических (по сходству) и метонимических (по смежности) переносов лексических значений.

2.5. Важной особенностью древней лексики является полиномия, то есть абсолютно синонимичное (дублетное) сосуществование разных названий одних и тех же понятий. Например, слово и термин масса утверждается в русском языке лишь к концу XVIII века, а «до этого разными авторами предлагались и использовались в данном смысле различные слова и выражения куча, гльљба, громада, собрание вещеества, толщза и т. д.» (ВЕСЕлИТСКИй 1967: 31). Примеры дублетности терминологии в Петровскую эпоху приводит Г. И. Шкляревский: оник, нуль; плоскость, поверхность, площадь, верховность, равность, равнина; полнолуние, полномесячие; помрачнение, потемнение, затмение; частица, атом, корпускул, пункт, монада. Автор отмечает и случаи многозначности терминов: круг - 'круг' и 'шар'; устье - 'морской залив', 'морской пролив', ‘устье реки' и 'жерло вулкана' (Шкляревский 1968: 21). До начала XIX века (до эпохи Пушкина) лексическая полиномия носителей языка не волновала, что свидетельствует о синкретичном невосприятии ими этого явления как логического противоречия. Однако в дальнейшем требование неполиномности терминов (и проявляющейся реже немногозначности термина) понимается как закон.

По убеждению В. В. Веселитского, период XVIII - начала XIX веков «является как бы переходным, подготовительным, когда новые единые общенациональные нормы лишь складываются, вырабатываются и закрепляются под пером выдающихся писателей, ученых, передовых мыслителей Кантемира, Ломоносова, Тредиаковского, Сумарокова, Новикова, Радищева и других. [...] В первой половине XIX в. (уже во времена Пушкина, и особенно в его творчестве) система национального литературного языка предстает уже в сложившемся, определенном виде» (ВЕСЕлитский 1967: 31). Но это, разумеется, не значит, что данная система достигла предела совершенства и застыла.

2.6. Еще одной важной особенностью перцептивно-логической эволюции лексического состава русского языка является логичное разрешение затруднения, связанного с таким хорошо известным явлением, как массовое попадание в древнерусскую лексику церковнославянизмов, которые автоматически становились абсолютными синонимами однокоренных исконно русских слов. Носители русского языка, демонстрируя альтернативность восприятия, подсознательно не могли мириться с абсолютной синонимией таких примеров. Разрешение затруднения состоялось в виде размежевания в основном стилистического (глас, град [высок.] - голос, город [нейтр.]), реже семантического (рождать $\neq$ рожать) или в виде исключения одного из эквивалентов (в настоящее время имеется, например, стилистически нейтральный 
русизм болото при отсутствии церковнославянизма блато и стилистически нейтральный церковнославянизм вред при отсутствии русизма веред - он сохранился в виде корня в привередливый, привередливо, привередничать и достаточно архаизированном привереда, но церковнославянизм плен, став стилистически нейтральным, полностью вытеснил древний русизм полон, который сохранился в украинском языке).

2.7. Следует сказать и о том, что в русском языке неизменно сокращается число просторечных слов и форм. Так, по наблюдениям Л. П. Крысина, слова и формы, относящиеся к группе «просторечие-1», типа радиво (вместо радио), колидор (вместо коридор), транвай (вместо трамвай), хочете (вместо хотите), выпимши (вместо выпивии), по происхождению нередко диалектные, встречаются в речи лишь некоторых представителей старшего поколения, в основном выходцев из деревни. Встречающееся в речи молодежи просторечие-2, например, поняла (вместо поняла), попутать (вместо перепутать), резетка (вместо розетка), более и не менее (вместо более-менее или устар. более или менее), согласно закона (вместо согласно закону), «представляет собой разновидность менее яркую, чем просторечие-1, и менее определенную по набору типичных для нее черт», то есть носит достаточно случайный характер (Крысин 2008: 20-23).

Понятно, что просторечие-1 постепенно сходит на нет вместе с его носителями, но важно, что следующему поколению оно, как правило, не передается. Это свидетельство логичного упорядочения русской лексики, которое происходит благодаря альтернативности восприятия: воспринимая обе семантически тождественные номинации и не находя для них дифференциального стилистического признака, позволяющего различать эти номинации в рамках нормативности, подавляющее большинство носителей языка, «не сговариваясь», конвенциализируют одну из этих двух номинаций как ненормативную (просторечную).

2.8. Весьма показательным по своей основывающейся на альтернативности восприятия логичности в развитии лексического яруса языка является отсутствие необратимости происходящих здесь изменений: если возникает потребность обозначить устаревшее, но затем возродившееся понятие - деархаизируется и соответствующее слово или значение многозначного слова. Так, по наблюдениям О. П. Ермаковой, деархаизируются слова губернатор, чиновник, купец, фискал, колдун, ведьма, ворожить и слова, от них производные, а также прямые значения слов религиозной тематики, в советское время употреблявшихся в основном переносно, например, причащзаться, всенощная, иконостас (Крысин 2008: 34-37).

2.9. В настоящее время продолжается и описанное несколькими абзацами выше развитие полисемии. Например, слова фигурант, середняк, пользователь, подписант, казнить, расстрелять, раскручивать, мигалка, нииа, хит, афганеи, газовик получили переносные значения. Наблюдается развитие иронической энантиосемии, например, схлопотать, получить, светить, угрожать, подарок. 
Однако, если в синонимической группе слов не вырабатываются либо стираются семантические или стилистические различия, возникает альтернативная по своей сути конкуренция номинаций, вследствие которой императивно побеждает лишь одна из них, например свитер при все менее частотном употреблении джемпер и пуловер. «В настоящее время не каждый носитель языка может объяснить, чем отличается пуловер от свитера, и почти никто не знает различий между джемпером и свитером» (то же можно сказать о словах бокал и фужер) (Крысин 2008: 53).

3. Таким образом, рассмотрение исторических преобразований русской лексики с точки зрения ее перцептивно-логической эволюции позволяет говорить о том, что обладающие альтернативным восприятием носители русского языка, стремясь обеспечить возможности смыслоразличения, логично оптимизируют русскую лексическую систему: 1) обобщенным характером лексических значений; 2) созданием абстрактной лексики; 3) образованием слов разнообразными деривационными средствами, в том числе от заимствований; 4) преодолением мнемонического недостатка путем использования двух доступных, метафорической и метонимической, возможностей создания новых лексических значений; 5) избавлением от логической противоречивости полиномии; 6) в основном стилистическим и реже семантическим различением церковнославянизмов и их исконно русских эквивалентов; 7) избавлением от просторечной лексики, коммуникативно не востребованной подавляющим большинством носителей языка; 8) логичным возвратом устаревших номинаций в случае возникновения коммуникативной потребности в них; 9) продолжением развития полисемии в настоящее время.

Представляется целесообразным дальнейшее, более глубокое, подробное и не статично фиксированное на современном состоянии, изучение перцептивно-логической эволюции русской лексики.

\section{Литература}

АХмАновА 1969 = АХмАновА О. С. Словарь лингвистических терминов. Москва, 1969. БАРулин 2008 = БАРулин А. Н. К аргументации полигенеза. В кн.: Разумное поведение и язык. Вып. 1. Коммуникативные системы животных и язык человека. Проблема происхождения языка. Москва, 2008. 41-58.

БУЛАХОВСКИй 1958 = БУЛАХОВСКИй Л. А. Исторический комментарий крусскому литературному языку. Киев, 1958.

БУРЛАК 2011 = БУРЛАК С. А. Происхождение языка. Факты, исследования, гипотезы . Москва, 2011.

БУСЛАЕВ 1959 = БУСЛАЕВ Ф. И. Историческая грамматика русского языка. Москва, 1959.

ВЕСЕЛИТСКИй 1967 = ВЕСЕЛИТСКИй В. В. Норма и вариант. Русский язык в школе 1967/5: 30-36.

Вишняцкий 2004 = Вишняцкий Л. Б. Человек в лабиринте эволющии. Москва, 2004. ГАК $1990=$ ГАК В. Г. Асимметрия в языке. В кн.: Лингвистический энциклопедический словарь. Москва, 1990. 47. 
ГОРБАЧЕВИЧ 1989 = ГОРБАЧЕВИЧ К. С. Нормы современного русского литературного языка. Москва, 1989.

КАРЦЕВСКИЙ 1965 = КАРЦЕВСКИЙ С. Об асимМетричном дуализме лингвистического знака. В кн.: ЗВеГинцЕВ В. А. (сост.) История языкознания XIX-XX веков в очерках и извлечениях. Ч. 2. Москва, 1965. 85-90.

Крысин 2008 = Крысин Л. П. (ред.) Современный русский язык. Активные прочессы на рубеже XX-XXI веков. Москва, 2008.

КуБряковА 1990а = КуБряковА Е. С. Парадигматика. В кн.: Лингвистический энциклопедический словарь. Москва, 1990. 366-367.

КуБРяковА 1990b = КуБРяковА Е. С. Синтагматика. В кн.: Лингвистический энцииклопедический словарь. Москва, 1990. 447-448.

Попов 2015 = Попов С. Л. Грамматические варианты в русском языке: когнитивноэволюционный аспект. Дис. ... докт. филол. наук. Харьков, 2015.

Рижский 1973 = Рижский И. С. Введение в круг словесности. В кн.: Хрестоматия по истории русского языкознания. Москва, 1973. 37-39.

РОЗЕНТАЛЬ-ТЕЛЕНКОВА 1985 = РОЗЕНТАЛЬ Д. Э., ТЕЛЕНКОВА М. А. СЛоварь-справочник лингвистических терминов. Москва, 1985.

СЕРЕБРЕННИКОВ 1970 = СЕРЕБРЕННИКОВ Б. А. К проблеме сущности яЗЫка. В кН.: Общчее языкознание. Формы существвования, функции, история языка. Москва, 1970. 9-95.

СЕЧенОВ 1952 = СЕЧеНОВ И. М. ЭЛеменТЫ мыслИ. В кН.: СЕЧЕНОВ И. М. ИЗбранные произведения. Т. 1. Физиология и психология. Москва, 1952. 272-426.

ТРУБАЧЕВ 1991 = ТРУБАЧЕВ О. Н. Этногенез и культура древнейших славян. Лингвистические исследования. Москва, 1991.

УОРФ 1960 = УОРФ Б. Л. Отношение норм поведения и мышления к языку. В кн.: Новое в лингвистике. Вып. 1. Москва, 1960. 135-168.

Филин 2006 = Филин Ф. П. Происхождение русского, украинского и белорусского языков. Историко-диалектологический очерк. Москва, 2006.

ФоминА 1990 = ФоминА М. И. Современный русский язык. Лексикология. Москва, 1990.

ЧЕРныХ 1962 = ЧЕРныХ П. Я. Историческая грамматика русского языка. Москва, 1962.

ШАнСКИй 1972 = ШАнский Н. М. Лексикология современного русского языка. Москва, 1972.

ШКЛЯРЕВСКИЙ 1968 = ШкЛЯРЕВСКИй Г. И. История русского литературного языка (первая половина ХVIII века). Харьков, 1968.

ШМЕЛЕВ 1977 = ШМЕЛЕВ Д. Н. Современный русский язык. Лексика. Москва, 1977.

Эльконин 2005 = Эльконин Д. Б. Детская психология. Москва, 2005.

Юдина $2010=$ Юдина Н. В. Русский язык в ХХІ веке. Кризис? Эволюичия? Прогресс? Москва, 2010.

ЯкоБСон $1985=$ ЯкоБсон Р. Лингвистические типы афазии. В кн.: ЯкоБсон Р. Избранные работыл. Москва, 1985. 287-300.

ЯкоБСон 1990 = ЯкоБсон Р. Два аспекта языка и два типа афатических нарушений. В кн.: Теория метафоры. Москва, 1990. 110-132.

Bloom 2004 = Bloom P. Can a dog learn a word? Science 304 (2004): 1605-1606.

Clark 1993 = Clark E. V. The Lexicon in Acquisition. Cambridge, 1993. 